\title{
EDITORIAL
}

\section{Nursing Now - a globaly campaign to raise the profile and status of nursing}

Nurses form the core of every healthcare system and make up the largest part of professional healthcare staff.

In 2016, the All-Party Parliamentary Group (APPG) published a report on Global Health called Triple Impact stating that nurses worldwide often expressed concerns about underestimating the benefits of nursing and being unable to exercise their full professional potential. They described limited access to education and training and limited opportunities for further professional development necessary to provide high-quality care (All-Party Parliamentary Group on Global Health, 2016). According to APPG, nursing problems also include the under-representation of nurses in management positions and their insufficient involvement in policymaking and decision-making at a local and national level. APPG concluded that empowering nurses would contribute to global health improvement, gender equality and economic growth.

In response to the Triple Impact report, the worldwide campaign "Nursing Now" was established. It is a three-year global project (2018-2020) that aims to improve health by increasing the profile and status of nursing. The Nursing Now campaign focuses on five key areas: ensuring that nurses and midwives have a more prominent voice in health policy-making; encouraging greater investment in the nursing workforce; advocating for more nurses; encouraging research that helps determine where nurses can have the greatest impact, and sharing examples of best nursing practice. Nursing Now is also a growing social movement (currently 89 countries involved) with an active network of groups seeking to influence global and national policies, encouraging managers in health care to invest into nursing and to introduce new models of care to maximize the benefits of nurses. The project Nursing Now will be completed on the occasion of the 200th anniversary of the birth of Florence Nightingale, in 2020, which the World Health Organization declared the Year of nurses and midwives. (nursingnow.org)

The Ministry of Health of the Czech Republic, in cooperation with professional societies, also joins the worldwide campaign Nursing Now. Minister of Health asked universities to increase the number of general nursing students. Implementation of experienced nurses' extended competences is under preparation. A photograph vernissage and a travelling exhibition from the nurses' lives and work and a short film about nurses work are prepared.

Students and the professional public are informed through university portals and Nursing Now conferences and other events are organized.

All these activities enhance the prestige of the nursing profession and improve the status of nursing. These activities contribute to the increase of certain nursing competences, which is often a common practice abroad (especially in home and primary care). Such activities may increase the attractiveness of these careers for young people and reduce leaving of the health care sector and thus support the reduction of nurses' deficit in health care, and aim to the goal of Nursing Now - Improving the health of the population.

Assoc. Prof. Lucie Sikorová, Ph.D. Department of Nursing and Midwifery Faculty of Medicine, University of Ostrava, Czech Republic

\section{References}

All-Party Parliamentary Group on Global Health. Triple impact: How developing nursing will improve health, promote gender equality and support economic growth. APPG: London; 2016 [cited 2019 Aug 25]. Available from: https://www.who.int/hrh/com-heeg/tripleimpact-appg/en/ 